se destrói quando é mantido em situação desconfortável"; que "a energia se esvai quando não é resposta"; e que "a mente torna-se opaca quando é usada de modo inapropriado", seremos capazes de perceber que "todas as coisas têm suas conseqüências... porém só os sábios sabem evitar seu desencadeamento; todos os eventos têm suas implicações, mas só os sábios sabem escolhêelas".

Assim, sugerimos a leitura de Estratégia e liderança: as lições dos mestres chineses na visão de um ocidental por todos aqueles que, preocupados com o correto administrar, estejam buscando, mais do que receitas de fácil aplicação e discutível eficiência, o entendimento profundo dessa atividade, suas concepções filosóficas e a raiz dos problemas encontrados nas organizações.

\section{ALLIANCE CAPITALISM: THE SOCIAL ORGANIZATION OF JAPANESE BUSINESS}

de MICHAEL L. GERLACH

Berkeley: University of California Press, 1992.

por Gilmar Masiero, Pesquisador e Professor da Universidade Estadual de Maringá, PR.

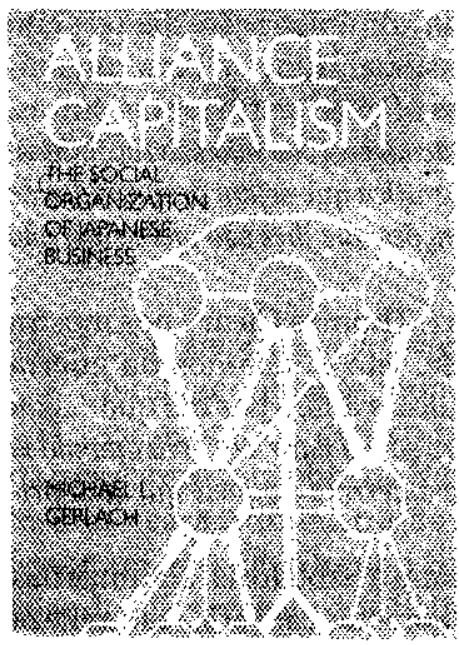

$\mathbf{N}$ os anos 80, o mundo acadêmico discutiu longamente se o excelente desempenho econômico do Japão era devido à sua grande capacidade de poupança e investimento no setor privado ou se era devido a políticas econômicas (industriais) orientadoras desse setor. Nos anos 90, mesmo sem termos uma solu- ção para os debates dos anos 80 , principalmente após as negociações entre os governos americano e japonês sobre os impedimentos estruturais ao livre comércio em 1989, surgem novas explicações para o melhor desempenho da economia japonesa. Este desempenho é devido à sua organização industrial, caracterizada por grandes grupos industriais, comerciais e financeiros.

A década passada também presenciou o surgimento de várias teorias sobre planejamento e administração estratégica. Esta última, nos últimos anos, tem se detido na análise da competitividade das nações e, mais recentemente, dos blocos econômicos, desde a Comunidade Européia, o NAFTA (North American Free Trade Agreement) e aASEAN (Association of South East Asian Nations), até o nosso familiar MERCOSUL. Devido à globalização dos negócios, conceitos como economias de escala, de escopo, fluxos de caixa globais e vantagens competitivas, muitas vezes advindas de orientações governamentais, são hoje senso comuns nas escolas de economia e administração do Oriente e do Ocidente.

Se, no nível das empresas isoladas, as estratégias japonesas são relativamente simples e de fácil compreensão, o mesmo não se pode afirmar sobre a atuação estratégica dos grandes grupos industriais. No nível da empresa, simplificadamente pode-se dizer que os japoneses foram aos Estados Unidos para estudar a maior produtividade das empresas americanas no imediato pósguerra. Voltaram para o Japão e, através de treinamento extensivo e intensivo, adaptaram técnicas americanas aos seus processos produtivos. No processo de adaptação essas técnicas foram "japonisadas" (melhoradas), permitindo hoje melhor desempenho da indústria japonesa.

No nível dos grupos industriais, os keiretsu, a estratégia adotada pelos japoneses, também simplificadamente, teria girado em torno da sua aglutinação forçada pela forte burocracia governamental, traduzida na atuação do MITI - Ministério do Comércio Internacional e da Indústria. Ministério e grandes grupos industriais selecionaram algumas indústrias e mercados-alvo e, através do esforço concentrado e direcionado, conseguiram participação em alguns mercados internacionais. Atualmente esta comunhão de interesses desenvolve produtos sofisticados, direcionados aos segmentos de mercado de renda elevada.

O dramático sucesso econômico japonês despertou a atenção das empresas e economias individuais do Ocidente. Enquanto a participação japonesa na produção mundial de manufaturados cresceu ininterruptamente ao longo dos últimos 40 anos, a produção americana ou de outros países europeus decresceu. Após o encontro no Hotel Plaza, em 1985, no qual o grupo das cinco nações economicamente mais poderosas do mundo (G-5) concordaram que o yen deveria ser valorizado, os japo- 
neses "invadiram" os mercados americanos e europeus, não permitindo, por meio de medidas protecionistas de toda a espécie, a mesma invasăo aos seus mercados. Uma dessas medidas é a sua peculiar organização industrial, estudada por Michael Gerlach.

O protessor-assistente de negócios intemacionais da Universidade da Califómia enfatiza o chamado capita* lismo de alianças, caracterizado por inovadoras e crescentes práticas de negócios entre grupos de empresas subsidiárias e/ou afiliadas, que trabalham sob coordenação única e atuam em diferentes setores econồmicos em escala mundial. Os mais conhecidos destes grupos empresariais, denominados keiretsu, estăo horizontalmente conectados (Mitsui, Mitsubishi, Sumitomo, DKB, Fuji, Sanwa etc.) e/ ou verticalmente integrados (Toyota, NEC, Toshiba etc.).

Estes grupos incluem empresas industriais diversificadas, que possuem no seu centro um grande banco e uma grande empresa trading. Gerlach demonstra que esses grupos funcionam através de uma série de canais ou redes de cooperaçäo que distinguem a economia japonesa daquelas ocidentais, $\mathrm{O}$ autor contribui para a compreensão do funcionamento do que se pode chamar de capitalismo intercorporativo e também procura desenvolver teoricamente, de forma interdisciplinar, esta nova forma de desenvolvimento capitalista.

Gerlach antecipa o resultado de seus estudos em The keiretsu: a primer, publicado, no inicio de 1992, pela Japan Society. Ao final de 1992 apresenta seu estudo completo em Alliance capitalism: the social organization of lapanese business, organizado em oito capítulos:

- Visão geral;

- Repensando o capitalismo de mercado;

- A organização das redes de negócios japonesas;

- A forma e estrutura básica dos Keiretsu;

- Padrões de formação de alianças;

- Desenvolvimento de novos negócios e inovação tecnológica no Japão;

- A empresa japonesa no contexto;

- Capitalismo de alianças e a economia japonesa.

Na síntese das descobertas do autor apresentadas em Visão Geral lê-se: "Evidências no capítulo 3 mostram que a posse cruzada de açoes para as grandes empresas japonesas é: a. duas vezes mais concentrada que nos Estados Unidos; $b$. quatro vezes mais estázeis; $c$. cinco vezes mais provâvel envolver posiçōes simultâneas de alta administração entre as mesmas empresas $e$ d. sete vezes mais provalvel serem reciprocas." Lê-se também: "Como o capítulo 4 indica, a proporģão de transaçöes que acontecem com empresas no mesmo grupo $e$ mais que dez vezes maior que a média das realizadas com em- presas de outros grupos, indicando um extremamente forte padrão de trocas preferencinis, que claramente tem importantes implicaçoes para como devemos entender a natureza dos mercados japoneses".

Essas e outras descobertas estão presentes neste trabalho que Gerlach desenvolve, contrastando dados das 200 maiores empresas manufatureiras e 50 maiores instituições financeiras japonesas com as equivalentes americanas. Os grandes grupos empresariais japoneses sắo o centro das atenções de Gerlach pelas razóes já esboçadas anteriormente, mas também porque "embora representem somente $10 \%$ das empresas industriais listadas na Bolsa de Valores de Tokyo, empresas formalmente afiliadas a um dos seis grandes grupos constituem mais de $40 \%$ do capital bancario total e mais da metade do total das vendas em certos setores manufatureiros (exemplo: aço e metais não ferrosos)".

Considerando essas descobertas e as tentativas japonesas de exportação de seu modelo de organização industrial para os demais países, o livro de Gerlach é oportuno e deve ser lido e refletido por todos os homens de negócio do Oriente e Ocidente, pelos administrädores, economistas e sociólogos interessados em respostas mais convincentes do que as apresentadas até então sobre o desenvolvimento econômico japonês do pós-guerra. $O$ trabalho merece ser lido não só pela sua grande receptividade nos meios acadêmicos e de negócios de todo mundo mas também pelo desafio empreendido pelo autor, de analisar estruturas, estratégias e instituições do e no desenvolvimento econômico japonês de uma forma interdiscplinar.

Evidenciar este ou aquele ponto da obra de Gerlach sem conhecer a totalidade dos trabalhos acadêmicos apropriadamente utilizados em sua argumentação é privilegiar determinada área de interesse ou este ou aquele autor mais internacionalmente conhecido. Neste trabalho o autor demonstra grande familiaridade com a literatura oriental e ocidental relacionada à dinâmica de crescimento das empresas e procura chamar a atenção para a provável existência de uma maior eficácia na forma organizacional japonesa quando contrastada com a norte-americana.

Talvez seu trabalho coloque excessiva ênfase nas relações entre grupos, a exemplo dos seguidores da teoria dos custos de transação na decisão de fazer ou comprar, como explicativo da dinâmica do capitalismo japonês. Talvez coloque pouca ênfase na habilidade japonesa de adaptação e desenvolvimento de tecnologias ocidentais simultaneamente à manutenção do próprio ethos cultural. $O$ que não pode deixar de ser dito é que, respeitadas as vontades do autor de enfatizar este ou aquele aspecto, as suas energias são eficazmente dispendidas no presente estudo. Ј 